\title{
Nanoferrites as Catalysts and Fillers for Polyaniline/Nanoparticle Composites Preparation
}

\author{
E. Falletta ${ }^{1}$, A. Ponti ${ }^{2}$, A. Sironi ${ }^{1}$, A. M. Ferretti ${ }^{2}$ and C. Della Pina ${ }^{1, *}$ \\ ${ }^{1}$ Dipartimento di Chimica, Università degli Studi di Milano, CNR-ISTM, via Golgi, 19, 20133, Milano, Italy \\ ${ }^{2}$ Laboratorio di Nanotecnologie, Istituto di Scienze e Tecnologie Molecolari, Consiglio Nazionale delle \\ Ricerche, Via G. Fantoli, 16/15-20138-Milan Italy
}

\begin{abstract}
In this paper, we report on the catalytic activity of $\mathrm{MFe}_{2} \mathrm{O}_{4}$ nanoparticles $(\mathrm{M}=\mathrm{Mn}, \mathrm{Ni}, \mathrm{Cu}, \mathrm{Zn}, \mathrm{Mg})$ in the oxidative polymerization of $\mathrm{N}$-(4-aminophenyl)aniline yielding polyaniline/nanoparticle composites. Hydrogen peroxide is used as the oxidizing agent and ferrite nanoparticles play the dual role of reaction catalysts and fillers. The obtained polyaniline/ $\mathrm{MFe}_{2} \mathrm{O}_{4}$ composites maintained the pristine size of the ferrite crystallites and showed a modest conductive behavior. Polyaniline/MFe $\mathrm{O}_{4}(\mathrm{M}=\mathrm{Mn}, \mathrm{Ni})$ composites displayed good dispersion of the nanoparticles in the polyaniline matrix and magnetic hardness intermediate between those of soft $\mathrm{M}=\mathrm{Fe}$ and hard $\mathrm{M}=\mathrm{Co}$ composites, evidencing the tunability of the magnetic properties.
\end{abstract}

Keywords: Catalysis, Composites, Ferrites, Nanoparticles, Polyaniline.

\section{INTRODUCTION}

Materials having both electrical and magnetic properties have attracted much interest thanks to their features combining the advantages of inorganic materials (mechanical strength, electrical and magnetic properties, as well as thermal stability) with those of organic compounds (flexibility, ductility and processing) [1]. Among them, intrinsically conducting polymers (ICPs) containing magnetic nanoparticles (NPs) exhibit many potential applications in electromagnetic interference shielding, [2] electrochromic devices [3] and non-linear optical systems [4]. Polyaniline (PANI) is one of the most investigated ICPs thanks to its extraordinary electrical properties, reversibly switching from an insulator to a conducting material by deprotonation/protonation processes $[5,6]$. It can exist in different forms: leucoemeraldine (totally reduced form, $x=1$ in Figure 1), emeraldine (half-oxidized form, $x=0.5$ in Figure 1), pernigraniline (totally oxidized form, $x=0$ in Figure 1) and many other intermediate structures (Figure 1).

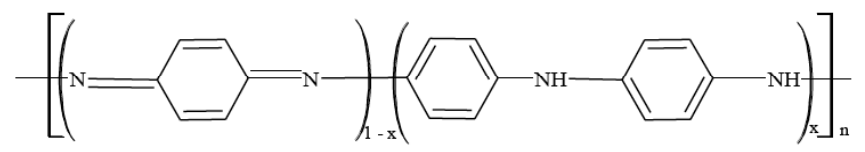

Figure 1: Polyaniline structures.

PANI/NPs composites are typically prepared by multi-step approaches involving NPs synthes is

"Address correspondence to this author at the Dipartimento di Chimica, Università degli Studi di Milano, CNR-ISTM, via Golgi, 19, 20133, Milano, Italy; Tel: +39 0250314410; Fax: +39 02 50314405;

E-mail: cristina.dellapina@unimi.it followed by aniline polymerization. The inorganic particles can be embedded during the polymerization process or in a subsequent step [7-10].

Inspired by our experience in the field of catalysis [11-13] and in the preparation of conducting polymers by innovative eco-friendly approaches, [14-16] we recently reported a new method to produce electrical and magnetic polyaniline nanocomposites, (PANI)/ $/ \mathrm{Fe}_{3} \mathrm{O}_{4}$ and $\mathrm{PANI} / \mathrm{CoFe}_{2} \mathrm{O}_{4}$, where the magnetic nanoparticles played the dual role of catalysts and magnetic fillers $[17,18]$.

In order to extend this study to PANI nanocomposites with different nanoferrites, we investigated the catalytic properties of nanosized $\mathrm{MFe}_{2} \mathrm{O}_{4}$, where $\mathrm{M}$ was $\mathrm{Mn}, \mathrm{Ni}, \mathrm{Cu}, \mathrm{Zn}$, and $\mathrm{Mg}$, in the $\mathrm{N}$-(4-aminophenyl)aniline oxidative polymerization to obtain electrical and magnetic $\mathrm{PANI} / \mathrm{MFe}_{2} \mathrm{O}_{4}$ nanocomposites.

\section{EXPERIMENTAL}

All chemicals were purchased by Sigma Aldrich and used as received without further purification. FT-IR spectra $\left(500-4000 \mathrm{~cm}^{-1}\right)$ were recorded by a JASCO FT/IR-410 spectrophotometer. The NPs morphology study was performed by transmission electron microscopy (TEM) using a Zeiss LIBRA-200FE microscope; the specimen were preparing by drop casting a dispersion of NPs or nanocomposite suspension in acetonitrile on a $5 \mathrm{~nm}$ carbon-film copper grid. TEM images were processed by means of a Imaging Platform software (Olympus). The metal content of all materials was determined by atomic 
absorption analysis on a AAnalyst3100 PerkinElmer spectrophotometer after sample mineralization in aqua regia. A Quantum Design MPMS XL-5 SQUID magnetometer was used to measure the magnetization isotherm of the nanoferrite samples between +50 and $50 \mathrm{kOe}$ at $5 \mathrm{~K}$. All the data were corrected for sample holder diamagnetic contribution. The dia-, para and superpara-magnetic contributions of the nanoferrite to the magnetization isotherm were identified by the method proposed by Fabian [19].

Powder X-ray diffraction (XRD) patterns were recorded using a Rigaku D IIIMAX horizontal-scan powder diffractometer with $\mathrm{Cu} \mathrm{K} \alpha$ radiation.

For conductivity measurements, $200 \mathrm{mg}$ of finely powdered samples were pressed between $13 \mathrm{~mm}$ anvils with force 10 ton for $30 \mathrm{~min}$. Each pellet was subjected to $2 \mathrm{~kg}$ weight. After $30 \mathrm{~min}$, the resistance $\mathrm{R}$ was measured by an AMEL338 multimeter and conductivity $\sigma$ was obtained by the following equation:

$$
\sigma=(1 / R)(\ell / A)
$$

where $\ell$ is the thickness of the disk and $A$ is the area of the disk base.

\section{$\mathrm{MFe}_{2} \mathrm{O}_{4}$ NANOPARTICLES (NPS) PREPARATION}

All $\mathrm{MFe}_{2} \mathrm{O}_{4}$ NPs were prepared according to a method reported in the literature [20]. Briefly, a solution of $\mathrm{FeCl}_{3} \cdot 6 \mathrm{H}_{2} \mathrm{O}\left(\left[\mathrm{Fe}^{+3}\right]=0.30 \mathrm{M}\right.$, solution $\left.\mathrm{A}\right)$ and $\mathrm{a}$ solution of $\mathrm{MCl}_{2} \cdot \mathrm{xH}_{2} \mathrm{O}\left(\left[\mathrm{M}^{+2}\right]=0.15 \mathrm{M}\right.$, solution $\left.\mathrm{B}\right)$, where $\mathrm{M}$ was $\mathrm{Mn}, \mathrm{Co}, \mathrm{Ni}, \mathrm{Mg}$ and $\mathrm{Zn}$, were prepared dissolving the appropriate amount of salts in $10 \mathrm{~mL}$ of $0.4 \mathrm{M} \mathrm{HCl}$, always maintaining the atomic ratio $\mathrm{Fe} / \mathrm{M}=$ 2. The two solutions were mixed and stirred at $80^{\circ} \mathrm{C}$ under inert atmosphere for $20 \mathrm{~min}$. Then, an aqueous solution of $1.5 \mathrm{M} \mathrm{NaOH}$ was quickly added until reaching $\mathrm{pH} 13$ and the mixture was maintained under vigorous stirring for $2 \mathrm{~h}$. Finally, a dark brown product was magnetically decanted, washed several times with deionized water until neutral $\mathrm{pH}$ of the liquor mothers and dried at $70^{\circ} \mathrm{C}$ in oven.
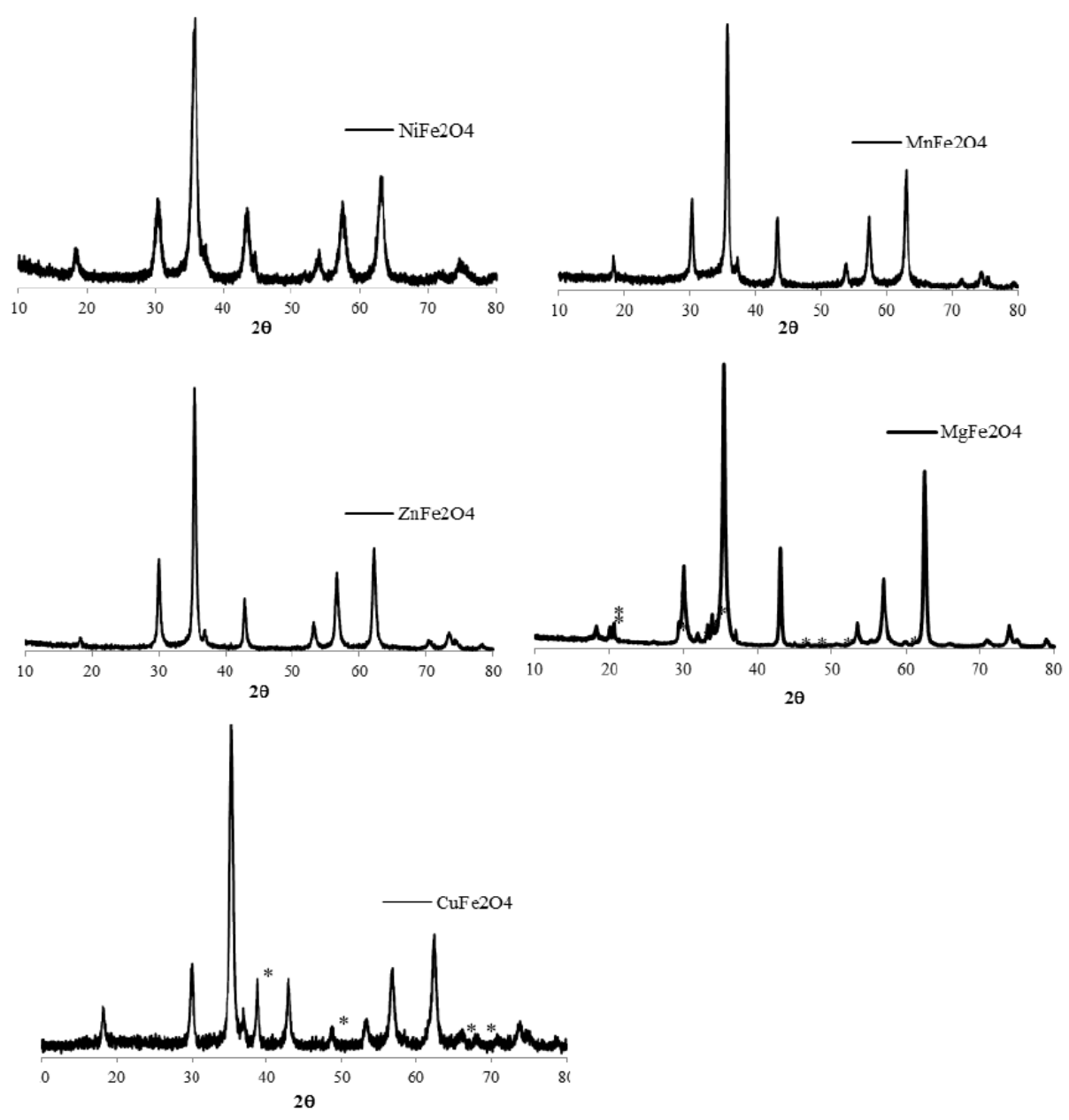

Figure 2: XRPD patterns of $\mathrm{MFe}_{2} \mathrm{O}_{4}$ nanoferrites. 


\section{SYNTHESIS OF PANI/NPS COMPOSITES}

$500 \mathrm{mg}$ of $\mathrm{N}$-(4-aminophenyl)aniline (aniline dimer, $\mathrm{AD}$ ) were dissolved in $90 \mathrm{~mL}$ of $0.03 \mathrm{M} \mathrm{HCl}$. Then, 1.4 $\mathrm{mL}$ of $\mathrm{H}_{2} \mathrm{O}_{2}\left(30 \% \mathrm{w} / \mathrm{w} ; \mathrm{H}_{2} \mathrm{O}_{2} / \mathrm{AD}=5\right.$ molar ratio) were added quickly followed by a proper amount of powdered $\mathrm{MFe}_{2} \mathrm{O}_{4} \mathrm{NPs}\left(\mathrm{AD} / \mathrm{MFe}_{2} \mathrm{O}_{4}=5\right.$ molar ratio). The mixture was stirred at room temperature for $24 \mathrm{~h}$. Finally, the reaction was stopped by the addition of acetone. After $20 \mathrm{~min}$ a dark solid was recovered by filtration, washed several times with deionized water and acetone until the mother liquor resulted to be colorless and finally dried in an oven $\left(80^{\circ} \mathrm{C}\right)$ for $6 \mathrm{~h}$.

The reaction was repeated in the absence of MNPs and, as reported in our previous work [16], a green solid material was obtained with $36 \%$ yield.

\section{RESULTS AND DISCUSSION}

\section{Characterization of $\mathrm{MFe}_{2} \mathrm{O}_{4}$ Nanoparticles}

All $\mathrm{MFe}_{2} \mathrm{O}_{4} \mathrm{NPS}$ were characterized by XRP diffraction and the results are reported in Figure $\mathbf{2}$.

These diffractograms show that all NPs have the cubic ferrite (spinel) structure [21-24]. The XRPD pattern of $\mathrm{M}=\mathrm{Mn}, \mathrm{Ni}, \mathrm{Zn}$ NP batches closely match the ferrite pattern showing that these comprise a pure ferrite phase, whereas those of $\mathrm{CuFe}_{2} \mathrm{O}_{4}$ and $\mathrm{MgFe}_{2} \mathrm{O}_{4}$ display additional peaks $\left({ }^{*}\right)$ that can be assigned to $\mathrm{CuO}$ in the case of $\mathrm{CuFe}_{2} \mathrm{O}_{4}$. The additional peaks displayed in $\mathrm{MgFe}_{2} \mathrm{O}_{4}$ pattern could not be identified despite extensive database search (diffrac.eva program).

The average diameters of $\mathrm{MFe}_{2} \mathrm{O}_{4} \mathrm{NPs}$, as determined by the Scherrer equation, and $\mathrm{Fe} / \mathrm{M}$ atomic ratios, as measured by AAS, are summarized in Table 1 .

Table 1: Mean Diameter (by XRPD) and Fe/M Atomic Ratio of $\mathrm{MFe}_{2} \mathrm{O}_{4} \mathrm{NPs}$ (by AAS)

\begin{tabular}{|c|c|c|}
\hline Ferrite NPs & Mean d (nm) & Fe/M (Atomic Ratio) \\
\hline \hline $\mathrm{MnFe}_{2} \mathrm{O}_{4}$ & 19.0 & 2.3 \\
\hline $\mathrm{NiFe}_{2} \mathrm{O}_{4}$ & 10.6 & 2.1 \\
\hline $\mathrm{CuFe}_{2} \mathrm{O}_{4}$ & 15.4 & 2.1 \\
\hline $\mathrm{ZnFe}_{2} \mathrm{O}_{4}$ & 18.4 & 1.8 \\
\hline $\mathrm{MgFe}_{2} \mathrm{O}_{4}$ & 19.3 & 1.9 \\
\hline
\end{tabular}

NPs were obtained with similar mean diameters and $\mathrm{Fe} / \mathrm{M}$ atomic ratios in good agreement with the stoichiometric value $(\mathrm{Fe} / \mathrm{M}=2)$.
TEM images of NPs show that all the samples are morphologically polydispersed and their spinel structure is confirmed by electron diffraction (ED) patterns (Figure 3). Table 2 summarizes the values of median, minimum and maximum diameter and standard deviation for all $\mathrm{MFe}_{2} \mathrm{O}_{4} \mathrm{NPs}$ as extracted by TEM images, except for $\mathrm{MgFe}_{2} \mathrm{O}_{4}$. In this latter case, diameters could not be reliably measured because the sample was largely aggregated, though single nanoparticles were visible. The results obtained for $M=$ $\mathrm{Mn}, \mathrm{Ni}$ are in agreement with the XRD achievements (Table 1), thereby indicating that in this case NPs are monocrystalline. On the other hand, the size of $\mathrm{CuFe}_{2} \mathrm{O}_{4} \mathrm{NPs}$ measured by TEM is slightly larger than that calculated from XRPD patterns by the Scherrer equation, thus suggesting a possible polycrystalline structure. Similarly, for $\mathrm{ZnFe}_{2} \mathrm{O}_{4} \mathrm{NPs}$ the large difference between XRPD and TEM size is firm evidence that these NPs are polycristalline.

Table 2: Median (Med d), Maximum (Max d), and Minimum (Min d) Diameter, and Standard Deviation (Std Dev) of $\mathrm{MFe}_{2} \mathrm{O}_{4} \mathrm{NPs}$ as Estimated from TEM Images

\begin{tabular}{|c|c|c|c|c|}
\hline $\begin{array}{c}\text { Ferrite } \\
\text { NPs }\end{array}$ & $\begin{array}{c}\text { Med d } \\
(\mathbf{n m})\end{array}$ & Std Dev(nm) & $\begin{array}{c}\text { Min d } \\
(\mathbf{n m})\end{array}$ & $\begin{array}{c}\text { Max d } \\
(\mathbf{n m})\end{array}$ \\
\hline \hline $\mathrm{MnFe}_{2} \mathrm{O}_{4}$ & 15.5 & 5.8 & 7.1 & 33.1 \\
\hline $\mathrm{NiFe}_{2} \mathrm{O}_{4}$ & 9.4 & 3.0 & 2.8 & 22.1 \\
\hline $\mathrm{CuFe}_{2} \mathrm{O}_{4}$ & 21.6 & not estimated & 10.5 & 45.1 \\
\hline $\mathrm{ZnFe}_{2} \mathrm{O}_{4}$ & 91.6 & not estimated & 8.9 & 33.7 \\
\hline
\end{tabular}

\section{Catalytic Polymerization}

Polyaniline can be produced following many different methods including chemical, electrochemical and enzymatic approaches [25]. Aniline polymerization by means of oxidants in stoichiometric amount is the oldest and still the most used procedure, although it involves serious drawbacks: toxic oxidants use, plenty of inorganic co-products and carcinogenic intermediates production (e.g., benzidine).

It was observed that the necessity to employ strong oxidizing agents in large amount is related to thermodynamic limitations [26, 27], consisting in the oxidation of aniline monomer to form dimeric species representing the most energy-demanding step of polymerization.

As we recently demonstrated, when $\mathrm{N}$-(4aminophenyl)aniline (aniline dimer, $A D$ ), a commercially available material, [28] is used as the starting reagent, hard oxidants can be replaced by 

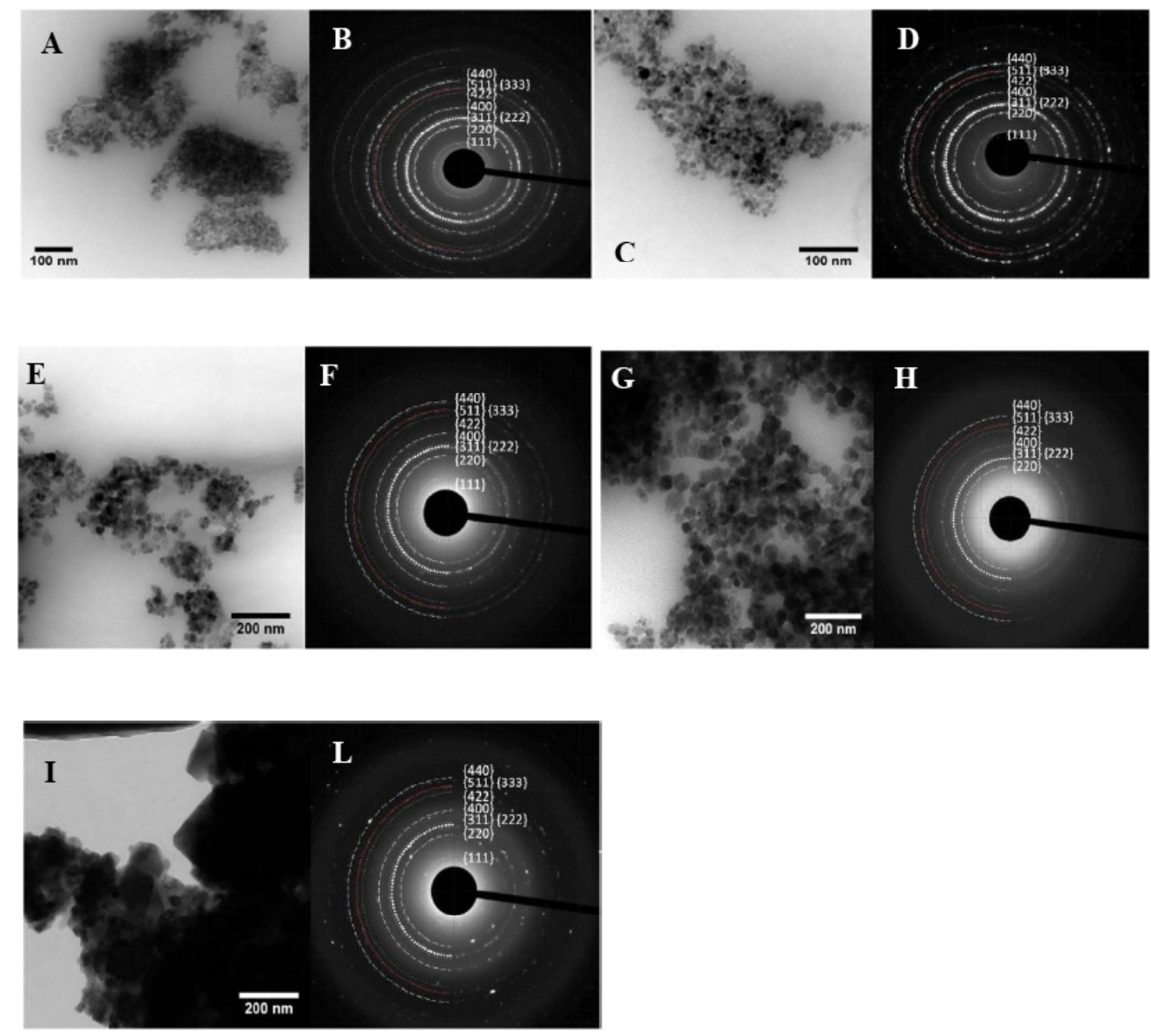

Figure 3: TEM images of $\mathrm{MnFe}_{2} \mathrm{O}_{4}(\mathrm{~A}), \mathrm{NiFe}_{2} \mathrm{O}_{4}$ (C), CuFe2O4 (E), ZnFe2O4 (G) and MgFe2O4 (I) NPs (scale bar = 100 nm and $200 \mathrm{~nm}$ ) and the corresponding electron diffraction patterns (B, D, F, H and $\mathbf{L}$ ).

greener ones (molecular oxygen or hydrogen peroxide) in the oxidative polymerization reaction with the aid of proper catalysts [16-18]. On this regard, $\mathrm{MFe}_{2} \mathrm{O}_{4}$ prepared as described in section Experimental- were employed both as the catalysts and (magnetic) fillers for the preparation of $\mathrm{PANI} / \mathrm{MFe}_{2} \mathrm{O}_{4}$ nanocomposites. Figure 4 displays the yield values as calculated according to Eq. (1):

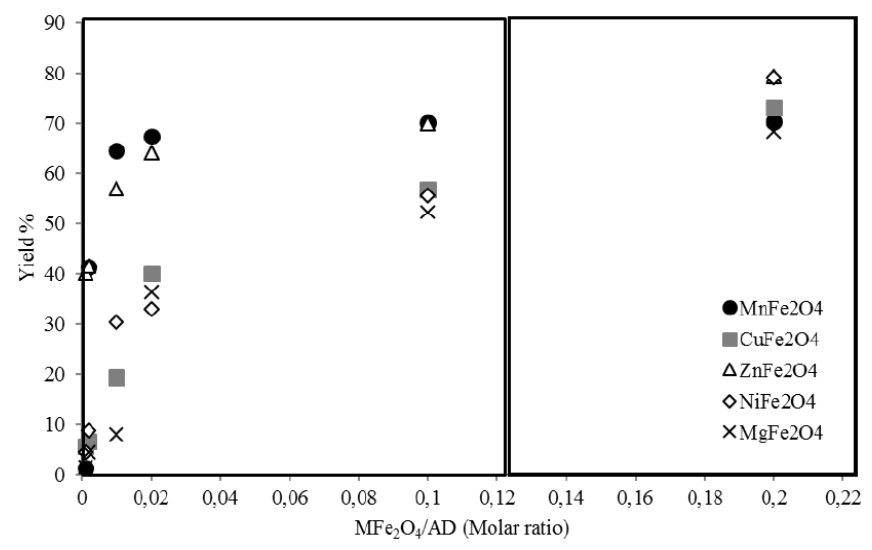

Figure 4: Dependence of the yield of $\mathrm{PANI} / \mathrm{MFe}_{2} \mathrm{O}_{4}$ composite on the MFe2O4/AD molar ratio.
Yield $\%=\left[\Sigma_{\text {(mass of insoluble product })} / \Sigma_{\text {(mass reagents) }}\right] \times 100$

As featured in our previous work [16], in the absence of any catalyst $\mathrm{N}$-(4-aminophenyl)aniline oxidative polymerization proceeded leading to polyaniline with $36 \%$ yield. Therefore, this value should be subtracted from the results reported in Figure 4 to evaluate the real catalytic activity of the NPs. When compared to the achievements observed using $\mathrm{Fe}_{3} \mathrm{O}_{4}$ and $\mathrm{CoFe}_{2} \mathrm{O}_{4}$ as the catalysts $[17,18]$, the NPs show a similar catalytic behaviour increasing with the $\mathrm{MFe}_{2} \mathrm{O}_{4}$ amount, up to reaching polymerization yields between 70 and $80 \%$. However, some differences are evident. On one hand, at low $\mathrm{MFe}_{2} \mathrm{O}_{4} / \mathrm{AD}$ molar ratio (0.01), $\mathrm{MnFe}_{2} \mathrm{O}_{4}$ and $\mathrm{ZnFe}_{2} \mathrm{O}_{4} \mathrm{NPs}$ led to reaction yields close to that obtained in the absence of any catalyst, on the other hand, all the other nanoferrites $(\mathrm{M}=\mathrm{Ni}, \mathrm{Cu}, \mathrm{Mg})$ seem to suppress the spontaneous ability of $\mathrm{H}_{2} \mathrm{O}_{2}$ to polymerize $A D$. Moreover, for all the $\mathrm{MFe}_{2} \mathrm{O}_{4} / \mathrm{AD}$ molar ratios investigated, the catalytic activity of these NPs always remained lower than that registered for $\mathrm{MnFe}_{2} \mathrm{O}_{4}$ and $\mathrm{ZnFe}_{2} \mathrm{O}_{4} \mathrm{NPs}$. Regarding $\mathrm{NiFe}_{2} \mathrm{O}_{4} \mathrm{NPs}$, 
an irregular behaviour was registered. Accordingly, on the left side of Figure 4 (low $\mathrm{MFe}_{2} \mathrm{O}_{4} / \mathrm{AD}$ molar ratios) Ni-ferrites exhibited similar catalytic activity as those of $\mathrm{Cu}$ - and Mg-ferrites, whereas at high $\mathrm{MFe}_{2} \mathrm{O}_{4} / \mathrm{AD}$ ratios, they were able to reach the catalytic performances of $\mathrm{Mn}$ - and $\mathrm{Zn}$-ferrite NPs. These unexpected results could be connected to different reasons. First of all, the presence of impurities (probably, single metal oxides $\mathrm{M}_{\mathrm{x}} \mathrm{O}_{\mathrm{y}}$ ) in some NPs could negatively affect their catalytic activity towards $N$ (4-aminophenyl)aniline oxidative polymerization. This inhibitory effect seems to prevail at low $\mathrm{MFe}_{2} \mathrm{O}_{4} / \mathrm{AD}$ molar ratios, whereas increasing the amount of NPs in the reaction mixture and, as a consequence, of $\mathrm{Fe}^{+3}$ sites, all the ferrites recovered their catalytic ability. However, if on the one hand the presence of inorganic impurities in nano-ferrites could justify the low catalytic performances of $\mathrm{CuFe}_{2} \mathrm{O}_{4}$ and $\mathrm{MgFe}_{2} \mathrm{O}_{4} \mathrm{NPs}$, on the other hand this explanation fails in the attempt to interpret the $\mathrm{NiFe}_{2} \mathrm{O}_{4} \mathrm{NPs}$ catalytic behaviour, because these NPs were free from impurities. A second possible reason that might disentangle the different catalytic behaviour could be related to the heterogeneous Fenton-like activity of ferrites, as recently demonstrated by $\mathrm{He}$ et al. [29]. The authors compared the different ability of $\mathrm{MFe}_{2} \mathrm{O}_{4}$ materials (where $\mathrm{M}$ was $\mathrm{Ti}, \mathrm{Cr}, \mathrm{Mn}$, $\mathrm{Co}$ and $\mathrm{Ni}$ ) to generate $\mathrm{OH}$ radicals. Even though various mechanisms have been proposed for explaining polyaniline formation, most of them agrees to consider that radicals play a key role [30-32]. The higher ability of $\mathrm{MnFe}_{2} \mathrm{O}_{4}$ and $\mathrm{CoFe}_{2} \mathrm{O}_{4} \mathrm{NPs}$ to produce
- $\mathrm{OH}$ radicals than $\mathrm{NiFe}_{2} \mathrm{O}_{4} \mathrm{NPs}$ seems to reflect our results. In fact, manganese ferrite allowed the highest activity in the catalytic $\mathrm{N}$-(4-aminophenyl)aniline oxidative polymerization, as well as cobalt ferrite, as previously demonstrated [18].

\section{PANI/NPs Composites Characterization}

RegardingPANI/NPs composites, FT-IR analyses revealed the polymeric matrix (polyaniline) to be in its conducting emeraldine form, as shown by the similar intensity of the two bands at $1498 \mathrm{~cm}^{-1}$ and $1484 \mathrm{~cm}^{-1}$ assigned to the $C=C$ stretching vibration modes of the quinoid and benzenoid groups, respectively, and by the strong electronic-like band at around $1144 \mathrm{~cm}^{-1}$ (Figure 5) [33].

Concerning XRPD patterns of PANI/NPs composite, it was possible to distinguish the broad peak at around $25^{\circ}$, assigned to amorphous polyaniline, as well as the presence of all the spinel diffraction peaks of nanoferrites discussed above (Figure 6). Moreover, the diffraction peaks of impurities observed in the diffractograms of $\mathrm{CuFe}_{2} \mathrm{O}_{4}$ and $\mathrm{MgFe}_{2} \mathrm{O}_{4}$ NPs (Figure 2) were not evident in the XRPD patterns of composites, showing that the impurities were not embedded in the composites and, therefore, did not impact the composite properties. As reported in Table 3 , it is evident that the mean diameter of the nanocrystals (as opposed to NPs), embedded in the composite, are close to those of pristine ferrites. Thus,

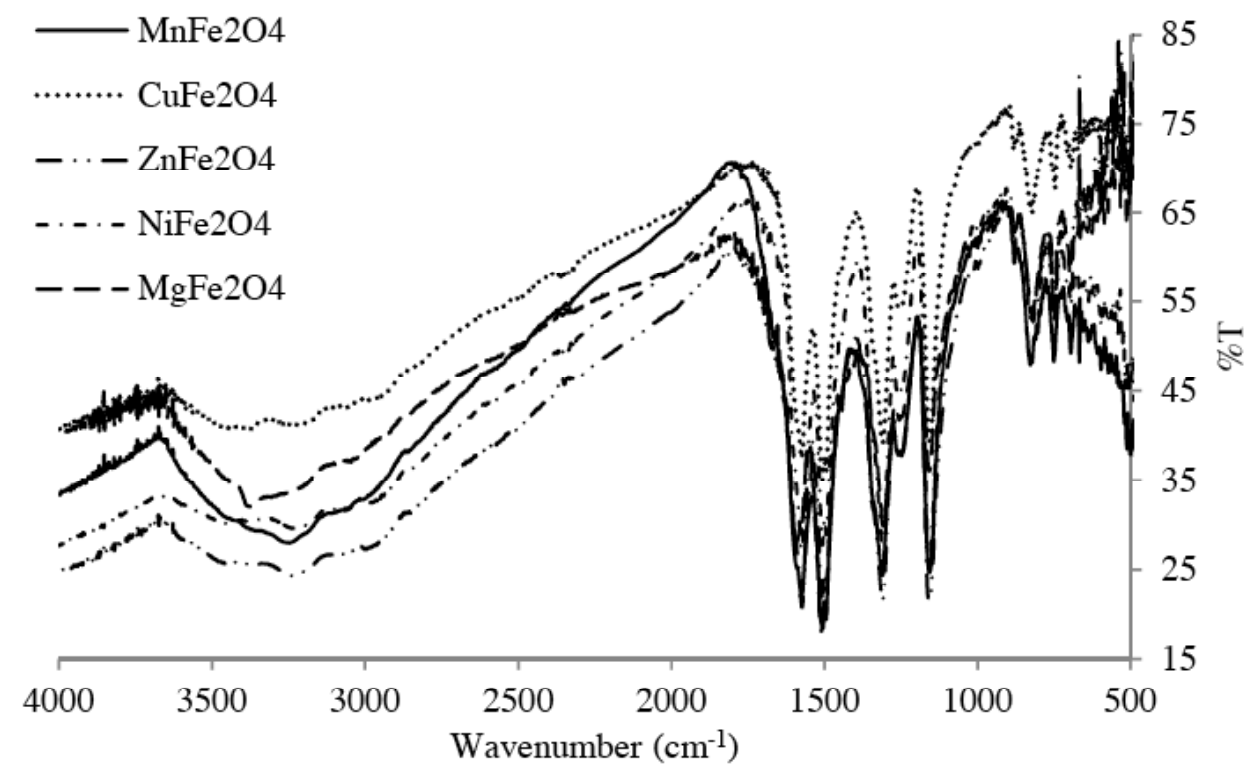

Figure 5: FT-IR spectra of PANI/MFe $\mathrm{O}_{4}$ composites obtained using a $\mathrm{MFe}_{2} \mathrm{O}_{4} / \mathrm{AD}$ molar ratio of 0.2 . 
the polymerization reaction environment did not affect the ferrite crystal size.

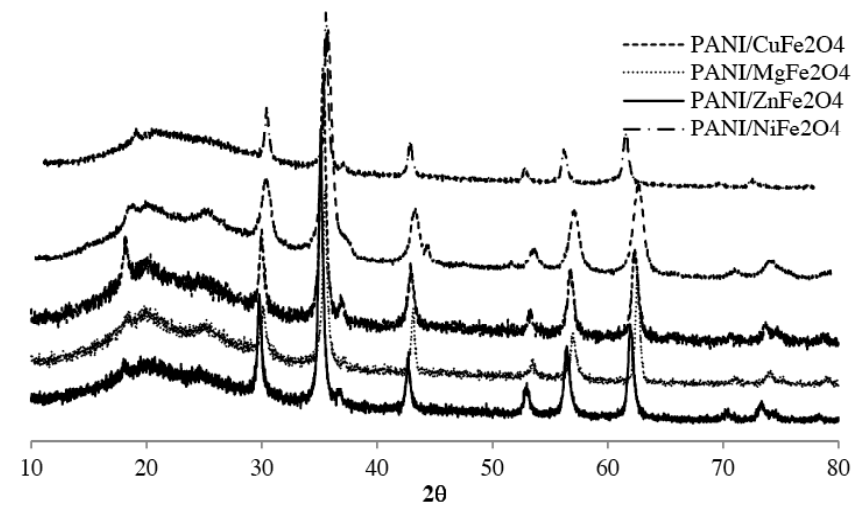

Figure 6: XRPD patterns of PANI/NPs composites obtained using a $\mathrm{MFe}_{2} \mathrm{O}_{4} / \mathrm{AD}$ molar ratio of 0.20 .

Table 3: Mean Diameter (by XRPD), Fe/M Atomic Ratio and $\mathrm{MFe}_{2} \mathrm{O}_{4}$ Content in Composites Obtained using the $\mathrm{MFe}_{2} \mathrm{O}_{4} / \mathrm{AD}$ Molar Ratio of 0.20 . *Theoretical Values

\begin{tabular}{|c|c|c|c|}
\hline Sample & $\begin{array}{c}\text { Mean d } \\
\text { (nm) }\end{array}$ & $\begin{array}{c}\text { Fe/M (atomic } \\
\text { ratio) }\end{array}$ & $\begin{array}{c}\mathbf{M F e}_{2} \mathrm{O}_{4} / \text { composite } \\
(\% \mathbf{w} / \mathbf{w})\end{array}$ \\
\hline \hline $\begin{array}{c}\mathrm{PANI} / \mathrm{MnFe}_{2} \mathrm{O} \\
4\end{array}$ & 17.9 & 2.0 & $23.9(25.0)^{\star}$ \\
\hline $\mathrm{PANI} / \mathrm{NiFe}_{2} \mathrm{O}_{4}$ & 10.4 & 2.3 & $18.9(22.2)^{\star}$ \\
\hline $\mathrm{PANI} / \mathrm{CuFe}_{2} \mathrm{O}_{4}$ & 15.6 & 2.8 & $20.9(24.6)^{\star}$ \\
\hline $\mathrm{PANI} / \mathrm{ZnFe} \mathrm{O}_{4}$ & 18.9 & 2.0 & $21.3(22.6)^{\star}$ \\
\hline $\begin{array}{c}\mathrm{PANI} / \mathrm{MgFe} \\
4\end{array}$ & 17.6 & 3.0 & $17.2(24.2)^{\star}$ \\
\hline
\end{tabular}

As far as the $\mathrm{Fe} / \mathrm{M}$ atomic ratio is concerned, if on the one hand the achievements for $\mathrm{MnFe}_{2} \mathrm{O}_{4}, \mathrm{NiFe}_{2} \mathrm{O}_{4}$ and $\mathrm{ZnFe}_{2} \mathrm{O}_{4} \mathrm{NPs}$ were in good agreement with the stoichiometric value ( $\mathrm{Fe} / \mathrm{M}=2)$, on the other hand for $\mathrm{MgFe}_{2} \mathrm{O}_{4}$ and $\mathrm{CuFe}_{2} \mathrm{O}_{4}$ it resulted to be higher than 2 . The loss of metal $\mathrm{M}$ suggests that the impurities observed in the case of $\mathrm{MgFe}_{2} \mathrm{O}_{4}$ and $\mathrm{CuFe}_{2} \mathrm{O}_{4}$ patterns (Figure 2) probably consist of M-containing oxides (or other species) which might dissolve in the reaction mixture during the polymerization reaction.

Likewise, atomic absorption spectroscopy showed that $\mathrm{MnFe}_{2} \mathrm{O}_{4}$ and $\mathrm{ZnFe}_{2} \mathrm{O}_{4} \mathrm{NPs}$ were completely embedded in the polymeric matrix $\left(\mathrm{MFe}_{2} \mathrm{O}_{4}\right.$ loss $\left.\cong 1 \%\right)$, whereas the amount of embedded $\mathrm{NiFe}_{2} \mathrm{O}_{4}, \mathrm{CuFe}_{2} \mathrm{O}_{4}$, and $\mathrm{MgFe}_{2} \mathrm{O}_{4} \mathrm{NPs}$ was lower than the expected value by 3,4 , and $7 \%$, respectively.

All these observations confirm the hypothesis that $\mathrm{MnFe}_{2} \mathrm{O}_{4}$ and $\mathrm{ZnFe}_{2} \mathrm{O}_{4}$ NPs acted as heterogeneous Fenton-like catalysts in the AD oxidative polymerization reaction, as well as their high catalytic activity was not related to their partial corrosion in the reaction mixture. Furthermore, the impurities present in $\mathrm{MgFe}_{2} \mathrm{O}_{4}$ and $\mathrm{CuFe}_{2} \mathrm{O}_{4} \mathrm{NP}$ batches inhibited the ability of $\mathrm{MFe}_{2} \mathrm{O}_{4}$ to catalyse the polymerization reaction, although not embedded in the composite. $\mathrm{NiFe}_{2} \mathrm{O}_{4} \mathrm{NPs}$ again displayed an intermediate character. As a general trend, by increasing the $\mathrm{MFe}_{2} \mathrm{O}_{4} / \mathrm{AD}$ molar ratio, the ferrite catalytic activity always prevailed.

Since $\mathrm{MnFe}_{2} \mathrm{O}_{4}$ and $\mathrm{NiFe}_{2} \mathrm{O}_{4}$ NPs displayed the highest and medium catalytic activity in the $A D$ oxidative polymerization, the corresponding composites were selected for TEM and magnetic investigations.

TEM images of $\mathrm{PANI} / \mathrm{MFe}_{2} \mathrm{O}_{4} \quad(\mathrm{M}=\mathrm{Mn}, \mathrm{Ni})$ composites, obtained using a $\mathrm{MFe}_{2} \mathrm{O}_{4} / \mathrm{AD}$ molar ratio of 0.20 , are reported in Figure 7 . In addition to conventional bright-field images, we also recorded images formed by collecting electrons which underwent a $30 \mathrm{eV}$ energy loss by interaction with the specimen. These energy-filtered images have higher contrast between the bright organic matrix and the dark inorganic NPs. The TEM images show that the NPs are well dispersed in the polymeric matrix and their morphology did not significantly changed. Electron diffraction patterns (not reported), confirmed that the
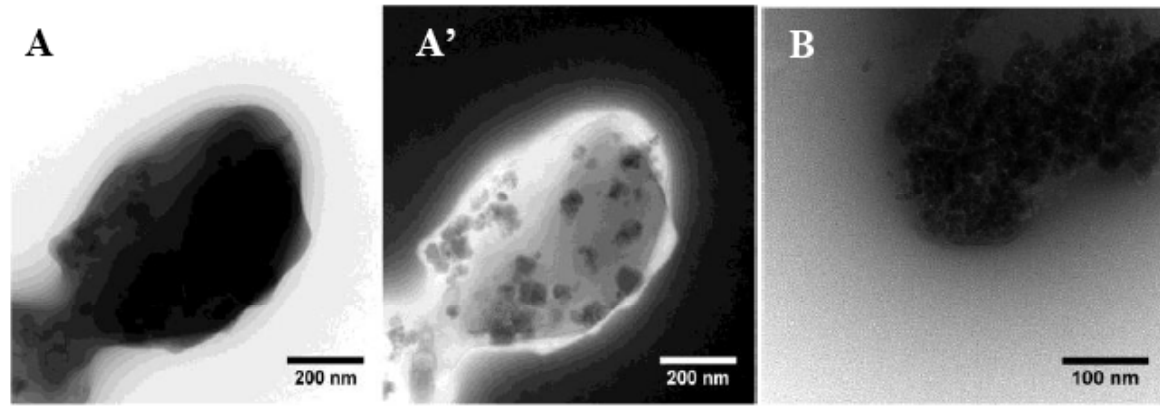

B'

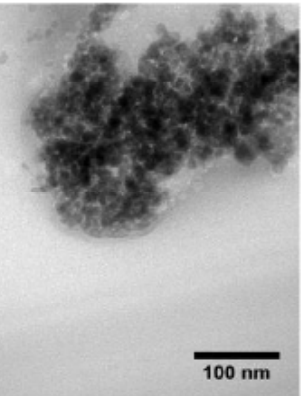

Figure 7: TEM images of $\mathrm{PANI} / \mathrm{MnFe}_{2} \mathrm{O}_{4}\left(\mathbf{A}, \mathbf{A}^{\prime}\right)$ and $\mathrm{PANI} / \mathrm{NiFe}_{2} \mathrm{O}_{4}\left(\mathbf{B}, \mathbf{B}^{\prime}\right)$ composites obtained using a $\mathrm{MFe}_{2} \mathrm{O}_{4} / \mathrm{AD}$ molar ratio of 0.20 . A and $\mathbf{B}$ are conventional bright-field images; $\mathbf{A}^{\prime}$ and $\mathbf{B}^{\prime}$ ' were recorded collecting electrons which underwent a 30 eV energy loss. 
NPs embedded in PANI matrix maintained the cubic ferrite structure.

The $T=5 \mathrm{~K}$ isothermal magnetization curves of $\mathrm{PANI} / \mathrm{MFe}_{2} \mathrm{O}_{4}(\mathrm{M}=\mathrm{Mn}, \mathrm{Ni})$ composites, obtained using a $\mathrm{MFe}_{2} \mathrm{O}_{4} / \mathrm{AD}$ molar ratio of 0.20 , are reported in Figure 8 and the main magnetic parameters are collected in Table 4. The coercivity $H_{c}$ is sizeable for cubic ferrites, making these composites intermediate between magnetically soft $\mathrm{PANI} / \mathrm{Fe}_{3} \mathrm{O}_{4}\left(H_{\mathrm{c}} \approx 0.1 \mathrm{kOe}\right)$ [17] and hard $\mathrm{PANI} / \mathrm{CoFe}_{2} \mathrm{O}_{4}\left(H_{\mathrm{c}} \approx 10 \mathrm{kOe}\right)$ [18]. The microcoercivity, i. e. the coercivity of individual NPs, is better represented by the remanence coercivity $H_{c r}$, which can be estimated by the $\Delta M$ method [34]. The $H_{\text {cr }}$ data confirm the intermediate magnetic nature of these composites and a considerable contribution of reversible mechanisms to magnetization inversion at low $(<1 \mathrm{kOe})$ fields.

The saturation $\left(M_{\text {sat }}\right)$ and remanent $\left(M_{\text {rem }}\right)$ magnetization again indicate an intermediate behavior between soft PANI/Fe ${ }_{3} \mathrm{O}_{4}$ and hard PANI/CoFe ${ }_{2} \mathrm{O}_{4}$, as evidenced by the $M_{\text {rem }} / M_{\text {sat }}$ ratio, which is ca. 0.1 and 0.5 for $\mathrm{M}=\mathrm{Fe}$ and $\mathrm{Co}$, respectively. The $M_{\text {rem }} / M_{\text {sat }}$ ratio for the present $\mathrm{PANI} / \mathrm{NiFe}_{2} \mathrm{O}_{4}$ and $\mathrm{PANI} / \mathrm{MnFe}_{2} \mathrm{O}_{4}$ is lower than that expected (about 0.5) for StonerWolfforth NPs, indicating the significant presence of superparamagnetic NPs even at $T=5 \mathrm{~K}$. The $M_{\text {sat }}$ value of $\mathrm{PANI} / \mathrm{MnFe}_{2} \mathrm{O}_{4}$, though lower than the bulk value $112 \mathrm{emu} / \mathrm{g}$, [35] is not unexpected in ferrite

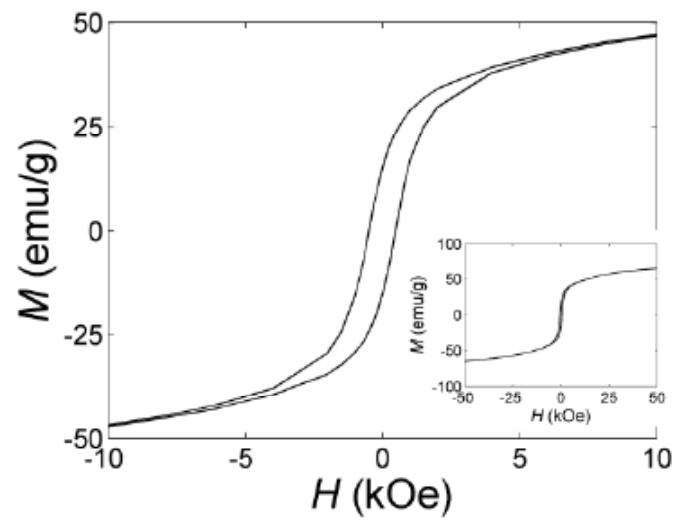

nanoparticles and usually attributed to surface effects [36]. For $\mathrm{PANI} / \mathrm{NiFe}_{2} \mathrm{O}_{4}, M_{\text {sat }}$ was instead found to be larger than the bulk value 56 emu/g [35]. This could be related to the $\mathrm{Fe} / \mathrm{Ni}$ ratio (Table 3 ) that is higher than the stoichiometric value. However, based on the bulk $M_{\text {sat }}=98 \mathrm{emu} / \mathrm{g}$ of $\mathrm{Fe}_{3} \mathrm{O}_{4}$ and the $\mathrm{Fe} / \mathrm{Ni}=2.3$ ratio, we expected $M_{\text {sat }}=59 \mathrm{emu} / \mathrm{g}$, that is lower than the observed one. Hence, the Fe excess is not able to fully account for the anomalously high $\mathrm{M}_{\text {sat }}$ of $\mathrm{NiFe}_{2} \mathrm{O}_{4}$.

The calculation of $M_{\text {sat }}$ from isothermal magnetization data of NPs could be affected by the presence of NPs in the superparamagnetic regime. To improve the calculation of $M_{\text {sat }}$, we resorted to a method [19] based on the analysis of the approach to saturation. At high-field, the magnetization $M$ is modeled as:

$$
M(H)=M_{\text {sat }}+x H+\alpha H^{\beta}
$$

where $X$ represents all dia- and para-magnetic contributions and the last term represents the approach to saturation. The $\beta$ parameter is -2 for homogeneous magnetization rotation and -1 for superparamagnetic ensembles. By fitting the last expression to the highfield data, we obtained the best-fit parameters collected in Table 5. The $\beta$ values indicate that both ferrimagnetic (blocked) and superparamagnetic NPs contribute to the approach to saturation and the corrected $M_{\text {sat }}$ value of $\mathrm{PANI} / \mathrm{NiFe}_{2} \mathrm{O}_{4}$ is closer to the bulk value.

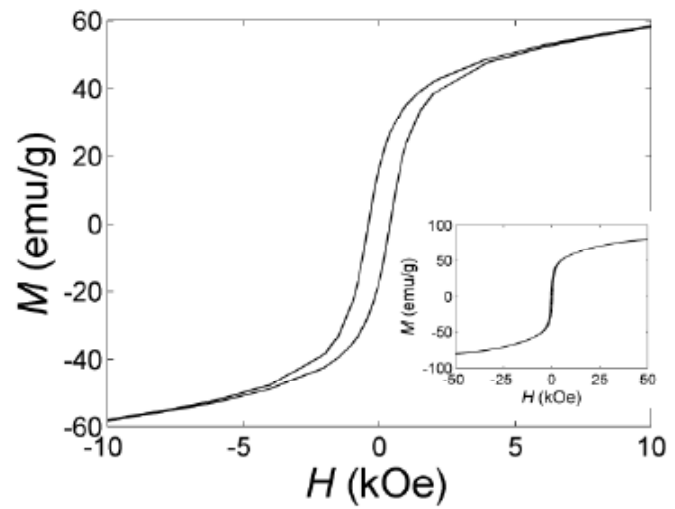

Figure 8: Isothermal magnetization curves of $\mathrm{PANI} / \mathrm{NiFe}_{2} \mathrm{O}_{4}$ (left) and $\mathrm{PANI} / \mathrm{MnFe}_{2} \mathrm{O}_{4}$ (right) composites, obtained using a $\mathrm{MFe}_{2} \mathrm{O}_{4} / \mathrm{AD}$ molar ratio of 0.20 . The subpanels show the entire isotherm between -50 and $+50 \mathrm{kOe}$.

Table 4: $\quad$ Magnetic Properties of Selected $(\mathrm{M}=\mathrm{Mn}, \mathrm{Ni}) \mathrm{PANI} \mathrm{MFe}_{2} \mathrm{O}_{4}$ Composites Derived from Magnetization Isotherm at $T=5 \mathrm{~K}$. ( ${ }^{\mathrm{a}}$ Mass Magnetization Referred to NP Mass (not Composite Mass). ${ }^{\mathrm{b}} \mathrm{M}_{\text {sat }}$ Actually is $M(50 \mathrm{kOe})$ as this Sample is not Completely Saturated at $50 \mathrm{kOe} .{ }^{c}$ Estimated using the $\Delta M$ Method [31]

\begin{tabular}{|c|c|c|c|c|c|c|}
\hline $\mathbf{M}$ & $\boldsymbol{M}_{\mathrm{sat}}{ }^{\mathrm{a}, \mathrm{b}}(\mathbf{e m u} / \mathbf{g})$ & $\boldsymbol{M}_{\mathrm{rem}}{ }^{\mathrm{a}}(\mathbf{e m u} / \mathbf{g})$ & $\boldsymbol{M}_{\mathrm{rem}} / \boldsymbol{M}_{\mathrm{sat}}$ & $\boldsymbol{H}_{\mathrm{c}}(\mathrm{kOe})$ & $\boldsymbol{H}_{\mathrm{cr}}{ }^{\mathrm{c}}(\mathrm{kOe})$ & $\boldsymbol{H}_{\mathrm{cr}} / \boldsymbol{H}_{\mathrm{c}}$ \\
\hline \hline $\mathrm{Ni}$ & 64.7 & 15.3 & 0.24 & 0.48 & 0.87 & 1.80 \\
\hline $\mathrm{Mn}$ & 80.4 & 16.9 & 0.21 & 0.39 & 0.75 & 1.90 \\
\hline
\end{tabular}


Table 5: Magnetization of selected $(\mathrm{M}=\mathrm{Mn}, \mathrm{Ni})$ $\mathrm{PANI} / \mathrm{MFe}_{2} \mathrm{O}_{4}$ Composites Values Corrected from Sample Dia-, Para-, and SuperparaMagnetic Contributions. [ ${ }^{\mathrm{a}}$ Mass Magnetization Referred to NP Mass (not Composite Mass). ${ }^{\mathrm{b}} M_{\text {sat }}$ Actually is $M(50 \mathrm{kOe})$ as Even the Blocked Part of the Sample Might not be Completely Saturated at $50 \mathrm{kOe}]$

\begin{tabular}{|c|c|c|c|c|}
\hline $\mathbf{M}$ & $\boldsymbol{\beta}$ & $\boldsymbol{M}_{\text {sat }}{ }^{\text {a,b }}(\mathbf{e m u} / \mathbf{g})$ & $\boldsymbol{M}_{\text {rem }}{ }^{\text {a }}(\mathbf{e m u} / \mathbf{g})$ & $\boldsymbol{M}_{\text {rem }} / \boldsymbol{M}_{\text {sat }}$ \\
\hline \hline $\mathrm{Ni}$ & -1.14 & 57.0 & 15.4 & 0.27 \\
\hline $\mathrm{Mn}$ & -1.12 & 72.2 & 16.9 & 0.23 \\
\hline
\end{tabular}

Conductivity values of all the $\mathrm{PANI} / \mathrm{MFe}_{2} \mathrm{O}_{4}$ composites synthesized using a $\mathrm{MFe}_{2} \mathrm{O}_{4} / \mathrm{AD}$ molar ratio of 0.2 were measured as described in the experimental part. All the materials resulted to be less conducting than traditional PANI prepared from aniline (typically $4.4 \mathrm{~S} / \mathrm{cm}$ ) [37] with values of conductivity between $2.0 \cdot 10^{-6}$ and $3.5 \cdot 10^{-7} \mathrm{~S} / \mathrm{cm}$, despite FTIR spectroscopy showed that the polymer was in the conducting emeraldine form. Although the lower conducting behaviour of the composites can be attributed to the presence of insulating nanoparticles, a real comparison among conductivity values of polyaniline prepared by different protocols and measurements recorded by various methods and under different conditions is very hard. In fact, it has been extensively demonstrated that PANI conductivity is affected by numerous factors, such as crystallinity degree, molecular weight, humidity level, branching presence, type and amount of dopants, as well as pressure applied on samples during measurements [38-40].

\section{CONCLUSIONS}

The catalytic behavior of $\mathrm{MFe}_{2} \mathrm{O}_{4} \mathrm{NPs}(\mathrm{M}=\mathrm{Ni}, \mathrm{Mn}$, $\mathrm{Cu}, \mathrm{Mg}$ and $\mathrm{Zn})$ in the oxidative polymerization of $\mathrm{N}-(4-$ aminophenyl)aniline to produce $\mathrm{PANI} / \mathrm{MFe}_{2} \mathrm{O}_{4}$ composites has been herein described. The difference in the catalytic performance of the various ferrites nanoparticles was attributed to two main factors: the purity level of the inorganic particles and their different ability to decompose $\mathrm{H}_{2} \mathrm{O}_{2}$ to $\cdot \mathrm{OH}$ radicals, involved in the polyaniline formation.

Ferrites seem to act as heterogeneous Fenton-like catalysts. More in detail, $\mathrm{MnFe}_{2} \mathrm{O}_{4}$ and $\mathrm{ZnFe}_{2} \mathrm{O}_{4}$ led to $\mathrm{PANI}$ in high yield, $\mathrm{NiFe}_{2} \mathrm{O}_{4}$ showed an intermediate behavior, whereas $\mathrm{CuFe}_{2} \mathrm{O}_{4}$ and $\mathrm{MgFe}_{2} \mathrm{O}_{4}$ efficiently worked only under specific conditions. All the ferrites, totally embedded in the polymeric matrix, retained their pristine crystal size as evinced by XRPD and TEM investigations. The (remanence) coercivity of $\mathrm{PANI} / \mathrm{NiFe}_{2} \mathrm{O}_{4}$ and $\mathrm{PANI} / \mathrm{MnFe}_{2} \mathrm{O}_{4}$ composites was found to beintermediate between those of magnetically soft PANI/Fe $\mathrm{O}_{3}$ and hard PANI/CoFe $\mathrm{O}_{4}$. Hence, our approach enables effective control of the magnetic hardness of composites with comparable specific magnetization. Finally, all PANI/ferrites composites exhibited a modest conducting behavior, even though the polymeric matrix was found to correspond to PANI in its emeraldine conducting form.

\section{ACKNOWLEDGMENTS}

The authors gratefully acknowledge financial support by Fondazione Cariplo (Milano, Italy) under grant n. 2012-0872 (Magnetic-nanoparticle-filled conductive polymer composites for EMI reduction).

\section{REFERENCES}

[1] Jiang J, Li L, Zhu M. Polyaniline/magnetic ferrite nanocomposites obtained by in situ polymerization. React FunctPolym 2008; 68(1): 57-62.

http://dx.doi.org/10.1016/j.reactfunctpolym.2007.10.010

[2] Miyauchi S, Aiko $\mathrm{H}$, Sorimashi $\mathrm{Y}$, Tsubatal. Preparation of barium titanate-polypyrrole compositions and their electrical properties. J Appl PolymSci 1989; 37(1): 289-293. http://dx.doi.org/10.1002/app.1989.070370123

[3] Shen K, Huang HT, Tseung ACC. A Study of Tungsten Trioxide and Polyaniline Composite Films I. Electrochemical and Electrochromic Behavior. J ElectrochemSoc 1992; 139(7): 1840-184. http://dx.doi.org/10.1149/1.2069508

[4] Peng $X$, Zhang Y, Yang J, Zou B, Xia PL, Li T, Yang J. Formation of nanoparticulate iron (III) oxide-stearate multilayer through Langmuir-Blodgett method. J PhysChem 1992; 96(8): 3412-3415 http://dx.doi.org/10.1021/j100187a043

[5] Wang W, Sarang PG, Jiao Q, Zhao B. Ferrite-grafted polyaniline nanofibers as electromagnetic shielding materials. J Mat Chem C2013; 1(16): 2851-2859. http://dx.doi.org/10.1039/c3tc00757

[6] Saini P, Choudhary V, Dhawan SK. Improved microwave absorption and electrostatic charge dissipation efficiencies of conducting polymer grafted fabrics prepared via in situ polymerization. Polym Advan Technol 2012; 23(3): 343-349. http://dx.doi.org/10.1002/pat.1873

[7] Wan M, Zhou W, Li J. Composite of polyaniline containing iron oxides with nanometer size. Synt Met 1996; 78: 27-31. http://dx.doi.org/10.1016/0379-6779(95)03562-1

[8] Aphesteguy JC, Jacobo SE. Composite of polyaniline containing iron oxides. Physica B 2004; 354: 224-227. http://dx.doi.org/10.1016/j.physb.2004.09.053

[9] Xia H, Cheng D, Xiao C, Chan HSO.Controlled synthesis of polyaniline nanostructures with junctions usingin situselfassembly of magnetic nanoparticles. J Mat Chem2005; 15: 4161-4166.

http://dx.doi.org/10.1039/b508629a

[10] Araújo ACV, de Oliveira RJ, Alves JS, Rodrigues AR, Machado FLA, Cabral FAO, de Azevedo WM. Synthesis, characterization and magnetic properties of polyanilinemagnetite nanocomposites. Synthetic Met 2010: 160: 685690.

http://dx.doi.org/10.1016/j.synthmet.2010.01.002

[11] Della Pina C, Falletta E. Gold-catalyzed oxidation in organic synthesis: a promise kept. Catal Sci Technol 2011; 1: 156471. http://dx.doi.org/10.1039/c1cy00283 
[12] Della Pina C, Falletta E, Rossi M. Update on selective oxidation using gold. ChemSoc Rev 2012; 41: 350-69. http://dx.doi.org/10.1039/C1CS15089H

[13] Comotti M, Della Pina C, Matarrese R, Rossi M. The Catalytic Activity of "Naked" Gold Particles. Angew Chemlnt Ed 2004; 43: 5812-5.

http://dx.doi.org/10.1002/anie.200460446

[14] Chen Z, Della Pina C, Falletta E, et al. Facile synthesis of polyanilineusinggoldcatalyst. J Catal 2008; 259: 1-4. http://dx.doi.org/10.1016/j.jcat.2008.07.006

[15] Della Pina C, Falletta E, Lo Faro M, Pasta M, Rossi M. Goldcatalysed synthesis of polypyrrole. Gold Bull 2009; 42: 27-33. http://dx.doi.org/10.1007/BF03214903

[16] Chen Z, Della Pina C, Falletta E, Rossi M. A green route to conducting polyaniline by copper catalysis. J Catal 2009; 267: 93-6. http://dx.doi.org/10.1016/j.jcat.2009.07.007

[17] Della Pina C, Rossi M, Ferretti AM, Ponti A, Lo Faro M, Falletta $\quad E$. One-pot synthesis of polyaniline/ $/ \mathrm{Fe}_{3} \mathrm{O}_{4}$ nanocomposites with magnetic and conductive behaviour. Catalytic effect of $\mathrm{Fe}_{3} \mathrm{O}_{4}$ nanoparticles. Synth Met 2012; 162: 2250-8.

http://dx.doi.org/10.1016/j.synthmet.2012.10.023

[18] Della Pina C, Ferretti AM, Ponti A, Falletta E. A green approach to magnetically-hard electrically-conducting polyaniline/ $\mathrm{CoFe}_{2} \mathrm{O}_{4}$ nanocomposites. Compos Sci Technol 2015; 110: 138-144

http://dx.doi.org/10.1016/j.compscitech.2015.02.007

[19] Fabian K. Approach to saturation analysis of hysteresis measurements in rock magnetism and evidence for stress dominated magnetic anisotropy in young mid-ocean ridge basalt. Phys Earth Planet Inter 2006; 154: 299-307. http://dx.doi.org/10.1016/j.pepi.2005.06.016

[20] Zhao SY, Lee DK, Kim CW, Cha HG, Kim YH, Kang YS. Synthesis of Magnetic Nanoparticles of $\mathrm{Fe}_{3} \mathrm{O}_{4}$ and $\mathrm{CoFe}_{2} \mathrm{O}_{4}$ and Their Surface Modification by Surfactant Adsorption. Bull Korean Chem Soc 2006; 27(2): 237-242. http://dx.doi.org/10.5012/bkcs.2006.27.2.237

[21] Wang $\mathrm{H}$, Huang J, Ding LY, Wang C, Han Y. Controlled preparation ofmonodisperse $\mathrm{CoFe}_{2} \mathrm{O}_{4}$ nanoparticles by a facile method. J Wuhan Univ Technol - Mater Sci Ed 2011; 26(2): 258-62.

http://dx.doi.org/10.1007/s11595-011-0209-1

[22] Deraz NM, Abd-Elkader OH. Investigation of Magnesium Ferrite Spinel Solid Solution with Iron-Rich Composition. Int J Electrochem Sci 2013; 8: 9071 - 9081.

[23] Bangale SV, Patil DR, Bamane SR. Preparation and electrical properties of nanocrystalline $\mathrm{MgFe}_{2} \mathrm{O}_{4}$ oxide by combustion route. ArchAppl Sci Res 2011; 3(5):506-513.

[24] Omer MIM, Elbadawi AA, Yassin OA. Synthesis and Structural Properties of $\mathrm{MgFe}_{2} \mathrm{O}_{4}$ Ferrite Nano-particles. J AppllndSci 2013; 1(4): 2328-4609.

[25] Della PinaC, FallettaE, RossiM.Conductive materials by metal catalyzed polymerization. Cat Today 2011; 160: 11-27. http://dx.doi.org/10.1016/i.cattod.2010.05.023

[26] Wei Y, Jang GW, Chan CC, Hsuen KF, Hariharan R, Patel SA, Whitecar CK. Polymerization of aniline and alkyl ring- substituted anilines in the presence of aromatic additives. $\mathrm{J}$ PhysChem 1994; 94: 7716-7721.

http://dx.doi.org/10.1021/j100382a073

[27] Wei $Y$, Tang $X$, Sun Y. Focke WW. A study of the mechanism of aniline polymerization. J PolymSci 1989; 27 2385-2396.

http://dx.doi.org/10.1002/pola.1989.080270720

[28] CAS Number 101-54-2.

[29] Zhonga Y, Liang X, He Z, Tana W, Zhua J, Yuan P, Zhu R, $\mathrm{He} \mathrm{H}$. The constraints of transition metal substitutions $(\mathrm{Ti}, \mathrm{Cr}$, $\mathrm{Mn}$, Co and $\mathrm{Ni}$ ) in magnetite on its catalytic activity in heterogeneous Fentonand UV/Fenton reaction: From the perspective of hydroxylradical generation. Appl Catal B2014; 612- 61: 8150- 151.

[30] Sun ZC, Geng YH, Li J, Wang XH, Jing XB, Wang FS Catalytic oxidization polymerization of aniline in an $\mathrm{H}_{2} \mathrm{O}_{2}$ $\mathrm{Fe}^{2+}$ system. J ApplPolymSci1999; 72:1077-1084 http://dx.doi.org/10.1002/(SICl)10974628(19990523)72:8<1077::AID-APP 12>3.0.CO;2-V

[31] Sun ZC, Geng YH, Li J, Jing XB, Wang FS. Chemical polymerization of aniline with hydrogen peroxide as oxidant. Synthetic Met1997; 84: 99-100.

http://dx.doi.org/10.1016/S0379-6779(96)03855-6

[32] Svoboda J, Bláha M, Sedláček J, Vohlídal J, Balcar H, MavGoležl, ŽigonM. New Approaches to the Synthesis of Pure Conjugated Polymers.ActaChimSlov2006; 53: 407-416.

[33] Salaneck WR, Liedberg $B$, Inganas $O$, Enandsson $R$, Lundstrom L, MacDiarmid AG, Halpem M, Somasin NLD. Physical Characterization of Some Polyaniline, $(\varnothing N)^{x}$.MolLiqCryst 1985; 121: 191-194. http://dx.doi.org/10.1080/00268948508074860

[34] Tauxe L, Mullender TAT, Pick T. Potbellies, wasp-waists, and superparamagnetism in magnetic hysteresis. J Geophys Res - Solid Earth 1996; 101: 571-83. http://dx.doi.org/10.1029/95JB03041

[35] Cullity BD, Graham CD. Introduction to magnetic materials. 2nd ed. IEEE Press-Wiley 2009.

[36] Batlle X, Labarta A. Finite-size effects in fine particles: magnetic and transport properties. J Phys D - Appl Phys 2002; 35: R15-42.

[37] Stejskal J, Gilbert RG. Polyaniline. Preparation of a conducting polymer (IUPAC technical report). Pure Appl Chem 2002; 74(5): 857-67. http://dx.doi.org/10.1351/pac200274050857

[38] Della PinaC, FallettaE, Polyaniline from tradition to innovation, ISBN: 978-1-63463-273-7, Nova Science Publishers, Inc. New York 2015.

[39] Della Pina C, Zappa E, Busca G, Falletta E. Electromechanical properties of polyanilines prepared by twodifferent approaches and their applicability in force measurements. Sens \& Act B 2014;201: 395-401. http://dx.doi.org/10.1016/j.snb.2014.04.105

[40] Falletta E, Costa P, Della Pina C, Lanceros-Mendez S. Development of high sensitive polyaniline based piezoresistive filmsby conventional and green chemistry approaches. Sens \& Act B A 2014; 220: 13-21. http://dx.doi.org/10.1016/..sna.2014.09.004 